\title{
EFEKTIFITASPELAYANANPUBLIK DIKECAMATAN SAMARINDA KOTA DI SAMARINDA
}

\author{
Ahmad Jubaidi \\ Email : jubaidiahmad@yahoo.co.id \\ UNIVERSITAS 17 AGUSTUS 1945 SAMARINDA
}

\begin{abstract}
The purpose of this study is to determine the effectiveness of KK, KTP, and AK services in Samarinda Kota sub district and its factors influencing the effectiveness of KK, KTP, AKservices.

The research used field research method which gives an overview on the effectiveness of KK, KTP, and AK services in Samarinda Kota sub district. Data collection techniques use observation techniques, interviews, and media questionnaires by selecting informants who play a role and are involved technically and functionally in service delivery to the community. The data obtained are then analyzed qualitatively and supported by quantitative data.

The results showed that service implementation in Samarinda Kota sub-district, especially in the field of population administration and civil registration is done in accordance with existing mechanism and regulation which have been determined by seeing some service indicator such as simplicity is in very safe category with $6.67 \%$ and certainty of service procedure and tariff cost are in accordance with the value of $88.33 \%$ and $70 \%$ respectively, the security and convenience of facilities and infrastructure are in safe and comfortable category with $65 \%$ and $73.33 \%$ respectively, openness about the ease of obtaining information and provisions services in the categories easy and explained if requested with the value of $71.67 \%$ and $63.33 \%$ respectively, economical about the cost of KK rates, ID cards, AK category Rp 10,000 - Rp 15,000, equitable fairness with a value of $60 \%$, the timeliness is in category 1 - 2 days, and the efficiency is an exact category with a value of $80 \%$. And the factors that affect the service is the resources apparatus, facilities and infrastructure, and public awareness.
\end{abstract}

Keywords: Effectiveness, Public Service 
Volume 4 Nomor 2, Oktober 2018

\section{PENDAHULUAN}

Pemerintah pada awalnya dibentuk untuk menghindari keadaan dimana sebuah wilayah yang dihuni oleh masyarakat serba mengalami kekacauan. Aktifitas pemerintah dalam upaya memelihara kedamaian dan keamanan suatu wilayah menjadi kewenangan utama baik secara internal maupun eksternal. Sebagaimana tujuan utama dibentuknya pemerintah adalah untuk menjaga suatu sistem ketertiban dimasyarakat bisa menjalani kehidupannya secara wajar.Dengan kata lain, pada hakikatnya adalah pelayanan kepada masyarakat yang merupakan fungsi primer dari pemerintah.

Dalam mengahadapi era globalisasi dan teknologi informasi yang penuh tantangan dan peluang, aparatur Negara sebagai pelayan masyarakat yang memberikan pelayanan sebaik- baiknya menuju good governence. Pelayanan yang diberikan kepada masyarakat setiap waktu selalu menuntut pelayanan public yang berkualitas dari birokrat yang dilakukan secara transparan dan akuntabilitas.

Berangkat dari fakta sementara,saat ini konsep desentralisasi dan otonomi daerah diartikulasikan oleh daerah untuk hanya terfokus pada usaha menata dan mempercepat pembangunan diwilayahnya masing-masing penerjemahan seperti ini ternyata belum cukup efisien dalam meningkatkan pelayanan publik kepada masyarakat.

Sebagai konsekuensi dari pelaksanaan Otonomi Daerah terlebih setelah ditetapkannya Undang-Undang nomor 32 Tahun 2004 tentang Pemerintahan Daerah, dimana Pemerintahan Daerah diberi kewenangan yang demikian luas oleh pemerintah pusat untuk mengatur rumahtangga daerahnya sendiri, termasuk didalamnya adalah pemberian pelayanan kepada masyarakat di daerahnya. Namun berbagai isu yang muncul di kalangan masyarakat, ternyata hak pelayanan yang diterima oleh masyarakat terasa belum memenuhi harapan semua pihak baik dari kalangan masyaraka tumum maupun dari kalangan pemerintah sendiri.

Perbaikan kinerja birokrasi pelayanan public akan mempunyai implikasi luas terutama dalam tingkat kepercayaan masyarakat kepada pemerintah sedangkan kurang baiknya kinerja birokrasi selama ini menjadi salah satu faktorpenting yang mendorong munculnyakrisis kepercayaan masyarakat kepada pemerintah. Pelayana masyarakat 
yang diberikan oleh aparatur pemerintah seringkali cenderung rumitseperti:a) Tatacara pelayanan, b) Rendahnya pendidikan aparat, c) Disiplin kerja. Hal ini sangat berpengaruh terhadap kualitas pelayanan umum di daerah.

Seiring dengan pelasanaan otonomi daerah, Samarinda menjadi Ibu kota Kalimantan Timur selalu dituntut untuk memberikan kesejahteraan kepada masyarakat, bangsa dan negara yang mencerminkan lewat kinerja aparat pemerintah dalam memberikan pelayanankepada masyarakatyangsesuaidengan perkembangan teknologi dan pertumbuhanserta peningkatan kebutuhan dasar masyarakat.Titik berat otonomi daerah saat ini adalah desa atau kecamatan, dimana pelayanan yang paling dekat dengan masyarakat dan secara langsung. Oleh karena itu,.Pelaksanaan pelayanan publik sangat penting untuk diperhatikan.

Tujuan penelitian adalah : (1) untuk mengetahui efektifitas pelayanan KK, KTP, dan Akta Kelahiran di Kecamatan Samarinda Kota, dan (2) untuk mengetahuif aktor-faktor yang mempengaruhi KK,KTP, dan Akta Kelahiran di Kecamatan Samarinda Kota.

\section{TINJAUAN PUSTAKA}

Definisi operasional yang dapat dijadikan sebagai acuan dalam penelitian, antara lain:

Adapun indikator yang dijadikan acuan dalam membahas kepuasan masyarakat, yaitu kriteria kualitas pelayanan berdasarkan keputusan Menteri Pendayagunaan Aparatur Negara No.25 Tahun2004 sebagai berikut:

a. Kesederhanaan, dalam arti prosedur atau tata cara pelayanan umum, diselenggarakan secara mudah dipahami,mudah dilaksanakan. Dikatakan pelayanan umum itu prima bila dalam pelaksanaan tidak menyulitkan, persyaratan yang harus dipenuhi pelanggan mudah,tidak bertele-tele.

b.Kejelasan dan kepastian, adanya kejelasan dan kepastianmengenai prosedur atau tatacara pelayanan umum,persyaratan pelayanan umum baik teknis maupun administrasi, unitkerja dan pejabatyang berwenang dan bertanggung jawab dalam pemberiaan pelayanan umum, dan tata cara pembayarannya, jadwal waktu 
penyelesaiannya, hak dan kewajiban bagi pemberi dan penerima pelayanan umum berdasarkan bukti-bukti penerimaan/permohonan kelengkapan.

c. Keamanan, proses dalam hasil pelayanan umum dapat memberikan keamanan, kenyamanan dan kepastian hukum. Adanya kepercayaan masyarakat dalam melaksanakan tugas sesuai prosedur yang jelas.

d.Keterbukaan, hal- hal yang berkaitan dengan proses pelayanan umum wajib diinformasikan secara terbuka agar mudah diketahui dan dipahami oleh masyarakat baik diminta maupun tidak diminta.

e. Ekonomis, dalam arti pengenaan biaya pelayanan umum harus ditetapkan secara wajar dengan memperhatikan: nilai barang dan jasa pelayanan umum dan tidak menuntut biaya yang tinggi diluar kewajaran, dan kondisi dan kemampuan masyarakat untuk membayar secara umum.

f. Keadilan yang merata, dalam arti cakupan atau jangkauan pelayanan umum harus diusahakan seluas mungkin dengan distribusi yang merata dan dilakukan secara adil,tidak membeda- bedakan kedudukan masyarakat karena setiap masyarakat mempunyai hak yang sama.

g. Ketepatan waktu, pelaksanaan pelayanan umum dapat diselesaikan dalam kurun waktu yang telah ditentukan, hal ini didukung oleh kemampuan pegawai dalam menyelasaikan tugas pelayanan dan ditunjang secara memadai.

2. Pelayanan public yang dimaksudkan dalam penelitian ini adalah pelayanan KK, KTP, dan Akte Kelahiran yang diberikan kepada masyarakat seperti yang tercantum di dalam Perda Kota Samarinda No.4tahun 2009 tentang penyelenggaraan Pendaftaran Penduduk dan Pencacatan Sipil dalam Kerangka Sistem Informasi Administrasi Kependudukan(SIAK).

3.Faktor-faktor yang mempengaruhi yang dimaksudkan dalam penelitian ini yaitu faktor pendukung dan faktor penghambat dalam pemberian pelayanan public kepada masyarakat seperti sarana dan prasarana kualitas sumber daya manusia dan kesadaran masyarakat. 


\section{METODE PENELITIAN}

Metode penelitian yang digunakan dalam penelitian ini menggunakan pendekatan kualitatif, dimana penelitian yang dilakukan bersifat deskriptif.

Penelitian dilaksanakan dari bulan Oktober sampai Desember 2017 yang berlokasi di Kecamatan Samarinda Kota di Samarinda.

Populasi dalam penelitian ini adalah para pejabat di Kecamatan Kecamatan Samarinda Kota di Samarinda, serta masyarakat yang berdomisili dan menerima pelayanan administrasi di Kecamatan Samarinda Kota.

Sampel adalah sebagian dari populasi untuk menjadi objek yang akan diteliti, pengambilan sampel menggunakan teknik purposive sampling, yaitu teknik penarikan sampel dengan cara sengaja atau menunjuk langsung kepada orang yang dianggap dapat mewakili populasi. Dalam penelitian ini peneliti mengambil 1 Kelurahan dan 2 Desa yang ada di Kecamatan Samarinda kota, sedangkan jumlah responden yang dipilih sebanyak 60 orang, adapun rinciannya sebagai berikut:

Data hasil penelitian dianalisis secara kualitatif serta didukung oleh data kuantitatif. Analisa kualitatif digunakan untuk menggambarkan peran pemerintah daerah dalam pelayanan publik, serta faktor- faktor yang mempengaruhi pelayananpublik diKecamatan Samarinda Kota di Samarinda. Sedangkan data kuantitatif yaitu dengan menggunakan tabel frekuensi untuk melihat tingkat presentase efektifitas pelayanan. Yang akan dipaparkan dalam bilangan presentase dengan rumus sebagai berikut : $\mathrm{P}=(\mathrm{F} / \mathrm{N}) \times 100 \%$, dimana $: \mathrm{P}=$ persentase $; \mathrm{F}=$ frekuensi; dan $\mathrm{N}=$ jumlah responden.

\section{HASIL PENELITIAN DAN PEMBAHASAN}

\section{Keadaan Umum Kecamatan Samarinda Ilir, Kota Samarinda}

\section{Keadaan Geografi}

Kota Samarinda meliputi tanah datar dan berbukit dengan ketinggian antara 10 $200 \mathrm{~m}$ dpl dan sekitar 41,12 persen dari luas wilayah adalah berbukit. Berdasarkan pada PP Nomor 21 Tahun 1987, Kota Samarinda terbagi menjadi 4 kecamatan dan pada tahun 1997 dimekarkan menjadi 6 kecamatan dengan 42 kelurahan. Selanjutnya 
dalam Perda Kota Samarinda Nomor 01 Tahun 2006 tentang pembentukan kelurahan dalam wilayah Kota Samarinda dan mengacu pada Peraturan Walikota (Perwali) Samarinda Nomor 10 Tahun 2006 tentang penetapan 11 kelurahan baru hasil dari pemekaran, maka jumlah kelurahan dalam wilayah Kota Samarinda menjadi 53 kelurahan. Pada tahun 2010, jumlah kecamatan dalam wilayah Kota Samarinda dimekarkan menjadi 10 kecamatan seiring dengan penetapan Kecamatan Sambutan, Kecamatan Samarinda Kota, Kecamatan Sungai Pinang, dan Kecamatan Loa Janan Ilir dalam Perda Nomor 02 Tahun 2010. Sampai tahun 2012, Kota Samarinda terdiri atas 10 kecamatan dengan 53 kelurahan.

\section{Pendidikan}

Sarana pendidikan yang adadi Kecamatan Samarinda Kota dari jenjang pendidikan tingkatTK sampai Perguruan Tinggi telah tersedia dengan rincian : 16 buah TK, 30 buah SD, 10 buah SLTP/Mts, 5 buah SMA/MA/SMK, dan 2 buah Perguruan Tinggi (BPS Kecamatan Samarinda Kota, 2015).

\section{Kesehatan}

Untuk melayani kesehatan penduduk diKecamatan Samarinda Kota tersedia beberapa fasilitas kesehatan yaitu :1 buah rumah sakit, 1 buah rumah bersalin, 1 buah poliklinik, 1 buah puskesmas, 3 buah puskesmas pembantu, dan 7 buah praktek dokter.

\section{Agama}

Kehidupan beragamadi daerah ini cukup rukun dan tentram, sarana peribadahan yang tersedia yaitu : 47 buah masjid, 15 buah musholla, dan 1 buah gereja.

\section{Mata Pencaharian Penduduk}

Mata pencaharian penduduk yang ada di Kecamatan Samarinda Kota beranekaragam, yaitu meliputi sektor pertambangan \& penggalian, perdagangan, hotel $\&$ restoran serta sektor jasa.

\section{SaranaTransportasi}

Sarana transportasi yang ada di Kecamatan Samarinda Kota yang tersedia itu sarana transportasi darat yang terdiri atas: sepeda motor (ojek),mobil, bus. Untuk angkutan mobil yang dilayani Angkutan Kota,Bis Sekolah, Angkutan Antar Kota. 
Dalam Propinsi (AKDP), serta Antar Kota Antar Propinsi ( AKAP).

\section{B. StrukturOrganisasiPemerintahKecamatan Samarinda Kota}

Struktur Pemerintahan Kecamatan Samarinda Kota disajikan pada Gambar 1 di bawah ini :

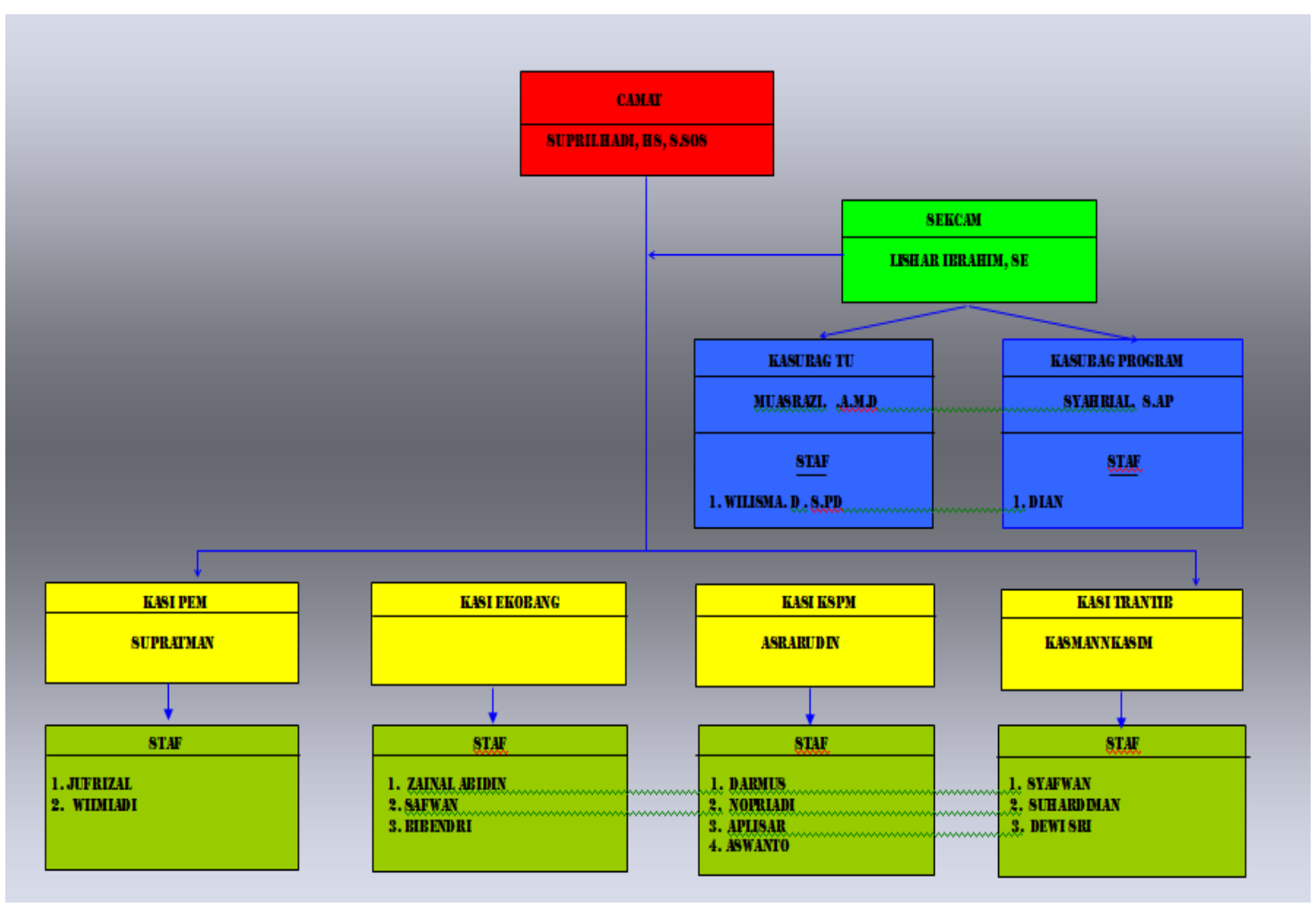

Kedudukan, tugas dan fungsi masing-masing adalah sebagai berikut:

\section{a. Camat}

Bertugas melaksanakan kewenangan pemerintahan yang dilimpahkan oleh Kepala Daerah dan tugas pemerintahan lainnya berdasarkan Peraturan Perundang-undangan; dan Fungsinya adalah : (1) pelaksanaan pelimpahan kewenangan pemerintah dari Kepala Daerah, (2) pelaksanaan tugas pemerintahan lainnya berdasarkan Peraturan Perundang-undangan; dan (3) Pelayanan penyelenggaraan pemerintah kecamatan.

\section{b. Sekretaris Kecamatan}

Bertugas mengelola ketatausahaan, penyusunan rencana dan program kerja serta memberikan pelayanan administrasi, urusan umum, perlengkapan dan kepegawaian serta keuangan kepada seluruh perangkat/aparatur kecamatan. Sekretaris kecamatan 
Volume 4 Nomor 2, Oktober 2018

membawahi 2 (dua) Sub Bagian yaitu:Tata Usaha dan Program, Evaluasi dan Pelaporan

\section{c. Seksi Pemerintahan}

Bertugasmembantu Camat dalam menyiapkan bahan perumusan kebijakan, pelaksanaan, evaluasi dan pelaporan urusan pemerintahan.

\section{d. Seksi Ketentraman dan Ketertiban}

Bertugasmembantu Camat dalam menyiapkan bahan perumusan kebijakan, pelaksanaan, evaluasi dan pelaporan urusan ketenteraman dan ketertiban

\section{e. Seksi Ekobang}

Bertugasmembantu Camat dalam menyiapkan bahan perumusan kebijakan, pelaksanaan, evaluasi dan pelaporan urusan ekonomi dan pembangunan.

\section{f. Seksi KSPM}

Bertugasmembantu Camat dalam menyiapkan bahan perumusan kebijakan, pelaksanaan, evaluasi dan pelaporan urusan kesejahteraan sosial dan pelayanan umum.

\section{g. Kelompok Jabatan Fungsional}

Kelompok jabatan fungsional terdiri dari sejumlah tenaga dalam jenjang jabatan fungsional yang terbagi dalam berbagai kelompok sesuai dengan bidangnya bertanggung jawab kepada Camat.

\section{KarakteristikResponden}

Karakteristik responden yang pada penelitian berjumlah 60 orang. Dimana dari jumlah tersebut memilki karakteristik yang berbeda-beda usia,jenis kelamin,tingkat pendidikan,dan jenis pekerjaan.

1. Berdasarkan usia yaitu 33,33\% (20-30 tahun), 25\% (31-40 tahun), $25 \%$ (41-50 tahun), $15 \%$ (51-60 tahun) dan 1,67\% (> 60 tahun).

2. Berdasarkan jenis kelamin terdiri atas $76,67 \%$ laki-laki dan $23,33 \%$ perempuan.

3. Berdasarkan tingkat pendidikan yaitu : 5\% SD; 25\% SLTP; 28,33\% SLTA; 6,67\% Diploma; 31,67\% S1 dan 3,33\% S2.

4. Berdasarkan pekerjaan terdiri atas : $31,67 \%$ petani/buruh; $35 \%$ ASN; $23,33 \%$ wiraswasta; $5 \%$ pelajar/mahasiswa; dan 5\% URT/tidak bekerja. 


\section{D.Pelayanan Publik di Kecamatan Samarinda Kota di Samarinda}

Pelayanan publik yang menjadi objek penelitian adalah pelayanan administrasi Kartu Keluarga(KK), Kartu Tanda Penduduk (KTP),dan Akte Kelahiran. Jumlah penduduk yang telah melakukan pelayanan administrasi kependudukan diKecamatan Samarinda Kota pada tahun 2015 yaitu sebanyak 61999 orang (KTP), 198 (KK) dan 5676 (Akta Kelahiran). Berdasarkan hasil wawancara dengan masyarakat dan dibenarkan oleh KepalaDesa dan Kelurahan adalah sebagai berikut:“ untuk pelayanan KTP,KK,dan AK, 90\% masyarakat sudah memiliki, tetapi masih ada masyarakat yang belum mengurus yang disebabkan mereka berfikir nanti saja mengurus jika merekabetul- betul membutuhkannya".

Tarif dasar dan waktu pelayanan KK, KTP, dan AK sesuai PerdaNo.4 tahun 2009 yaitu ada perbedaanyaitu di desa penetapan tarif 1 kali pelayanan dipungut sehargaRp. 10.000 (waktu pelayanan 1-2 hari), dan untuk wilayah kelurahan digratiskan (waktu pelayanan 1-2 hari).

\section{E. TanggapanResponden tentang Efektifitas Pelayanan Publik DiKecamatan Samarinda Kota}

Persepsi masyarakat terhadap efektifitas pelayanan public diKecamatan Samarinda Kota akan tergambar dalam uraian dengan mengacu pada 7indikator, yaitu: kesederhanaan; kejelasan dan kepastian; keamanan; keterbukaan; ekonomis; keadilan yang merata; dan ketepatan waktu.

1. Kesederhanaan pelayanan dalam artian bahwa prosedur atautata cara pelayanan umum diselenggarakan secara mudah dipahami, mudah dilaksanakan.

\begin{tabular}{|l|c|c|}
\hline Tanggapan Responden & Frekuensi & Persertase \\
\hline \multicolumn{2}{|c|}{ KESEDERHAAN (KEMUDAHAAN PROSEDUR) } \\
\hline TidakMudah & 2 & 3,33 \\
KurangMudah & 9 & 15 \\
Mudah & 45 & 75 \\
SangatMudah & 4 & 6,67 \\
\hline \multicolumn{2}{|c|}{ KEJELASAN DAN KEPASTIAN PETUGAS } \\
\hline
\end{tabular}


AL - ULUM ILMU SOSIAL DAN HUMANIORA

ISSN: $2476-9576$

Volume 4 Nomor 2, Oktober 2018

\begin{tabular}{|c|c|c|}
\hline TidakSesuai & - & - \\
\hline KurangSesuai & 4 & 6,67 \\
\hline Sesuai & 53 & 88,33 \\
\hline SangatSesuai & 3 & 5 \\
\hline \multicolumn{3}{|c|}{ KEAMANAN } \\
\hline TidakAman & 3 & 5 \\
\hline Kurang Aman & 10 & 16,6 \\
\hline Aman & 39 & 7 \\
\hline \multirow[t]{4}{*}{ SangatAman } & 8 & 6 \\
\hline & & 5 \\
\hline & & 13,3 \\
\hline & & 3 \\
\hline \multicolumn{3}{|c|}{ KEPASTIANBIAYA/TARIF PELAYANAN } \\
\hline TidakSesuai & 2 & 3,3 \\
\hline Kurang Sesuai & 12 & 3 \\
\hline Sesuai & 42 & 2 \\
\hline \multirow[t]{5}{*}{ SangatSesuai } & 4 & 0 \\
\hline & & 7 \\
\hline & & 0 \\
\hline & & 6,6 \\
\hline & & 7 \\
\hline \multicolumn{3}{|c|}{ KENYAMANAN SARANAPRASARANADANKERAMAHANAPARATUR } \\
\hline TidakNyaman & 1 & 1,6 \\
\hline KurangNyaman & 12 & 7 \\
\hline Nyaman & 44 & 2 \\
\hline \multirow[t]{4}{*}{ SangatNyaman } & 3 & 0 \\
\hline & & 73,3 \\
\hline & & 3 \\
\hline & & 5 \\
\hline \multicolumn{3}{|c|}{ KEMUDAHANMEMPEROLEHINFORMASI } \\
\hline
\end{tabular}


Volume 4 Nomor 2, Oktober 2018

\begin{tabular}{|c|c|c|}
\hline TidakMudah & 4 & 6,6 \\
\hline Kurang Mudah & 6 & 7 \\
\hline Mudah & 43 & 1 \\
\hline \multirow[t]{5}{*}{ SangatMudah } & 7 & 0 \\
\hline & & 71,6 \\
\hline & & 7 \\
\hline & & 11,6 \\
\hline & & 6 \\
\hline \multicolumn{3}{|c|}{ KEJELASAN TENTANGKETENTUAN PELAYANAN ADM } \\
\hline $\begin{array}{l}\text { TidakPernahadapemberi } \\
\text { tahuandan penjelasan } \\
\text { Hanya }\end{array}$ & - & - \\
\hline diberitahukantanpa & 5 & 833 \\
\hline penjelasan & & \\
\hline DijelaskanJikaDiminta & 38 & 63,33 \\
\hline \multicolumn{3}{|l|}{ SelaluDijelaskan } \\
\hline & 17 & 28,33 \\
\hline \multicolumn{3}{|c|}{ TanggapanResponden tentang KeadilanBiayaYang Telah Di } \\
\hline \multicolumn{3}{|c|}{ TetapkanDengan Dibayarkan } \\
\hline SelaluTidak Sesuai & - & - \\
\hline Kadang -KadangSesuai & 13 & 21,6 \\
\hline Banyak Sesuai & 29 & 7 \\
\hline \multirow[t]{4}{*}{ SelaluSesuai } & 18 & 48,3 \\
\hline & & 3 \\
\hline & & 3 \\
\hline & & 0 \\
\hline \multicolumn{3}{|c|}{ KEADILANDALAMHALPEMBERIANLAYANAN } \\
\hline TidakAdil & 5 & 8,3 \\
\hline KurangAdil & 10 & 3 \\
\hline
\end{tabular}


AL - ULUM ILMU SOSIAL DAN HUMANIORA

ISSN: $2476-9576$

Volume 4 Nomor 2, Oktober 2018

\begin{tabular}{|c|c|c|}
\hline Adil & 36 & 16,6 \\
\hline \multirow[t]{5}{*}{ SangatAdil } & 9 & 7 \\
\hline & & 6 \\
\hline & & 0 \\
\hline & & 1 \\
\hline & & 5 \\
\hline \multicolumn{3}{|c|}{ KETEPATAN WAKTU PELAYANAN } \\
\hline KurangTepat & - & - \\
\hline Kadang-2Tepat & - & - \\
\hline Tepat & 48 & 8 \\
\hline \multirow[t]{3}{*}{ SangatTepat } & 12 & 0 \\
\hline & & 2 \\
\hline & & 0 \\
\hline \multicolumn{3}{|c|}{ KECEPATAN PELAYANAN } \\
\hline TidakCepat & 1 & 1,6 \\
\hline KurangCepat & 28 & 7 \\
\hline Cepat & 30 & 46,6 \\
\hline \multirow[t]{5}{*}{ SangatCepat } & 1 & 6 \\
\hline & & 5 \\
\hline & & 0 \\
\hline & & 1,6 \\
\hline & & 7 \\
\hline \multicolumn{3}{|c|}{ KECAKAPAN( KEMAMPUAN )PETUGAS } \\
\hline \multicolumn{3}{|c|}{ DALAMMEMBERIKAN PELAYANAN } \\
\hline TidakCakap & 1 & 1,6 \\
\hline KurangCakap & 1 & 7 \\
\hline Cakap & 57 & 1,6 \\
\hline SangatCakap & 1 & 7 \\
\hline & & 9 \\
\hline & & 5 \\
\hline
\end{tabular}




\begin{tabular}{|c|c|c|}
\hline & 1,6 \\
& & 7 \\
\hline
\end{tabular}

\section{F. Harapan masyarakat terhadap pelayanan publik yang dilakukan olehaparatur di Kecamatan Samarinda Kota}

Dalam lingkungan masyarakat yang banyak terdapat lapisan atau strata maupun golongan-golongan individu masyarakat yang memiliki kepribadian atau pemikiran yang berbeda-beda pula. Atas dasar itulah, terjadi pula berbagai perbedaan mengenai harapan masyarakat kedepannya mengenai pelayanan publik diKecamatan Samarinda Kota, yaitu : (1) semoga pelayanannya lebih di tingkatkan lagi dari sebelumnya; dan (2) petugas lebih mengutamakan keadilan jangan ada pandang bulu dan golongan.

\section{G.Faktor-Faktor yang Mempengaruhi Efektifitas Pelayanan Publik di Kecamatan Samarinda Kota}

Pelaksanaan tugas pelayanan dalam strukutur organisasi tidak selamanya berjalan dengan baik seperti yang kita harapkan, terkadang dalam pelaksanaannya aparat pemerintah mengalami kendala-kendala atau faktor penghambat, namun disamping itu ada pula faktor-faktor yang menjadi pendukung jalannya prosedur pelayanan. Faktorfaktor penghambat ataupun pendukung jalannya pelayanan di Kecamatan Samarinda Kota yaitu :

\section{Sumber daya aparatur}

Untuk memberikan pelayanan yang maksimal kepada masyarakat sangat dibutuhkan aparatur pemerintah yang memiliki kualitas sumberdaya manusia yang handal, untuk itulah kemudian dapat dikatakan keberhasilan suatu pelayanan salah satunya sangat ditentukan oleh kualitas aparat yang ditunjuk sebagai pelayanan publik. Kemampuan dalam hal ini yaitu baik dari segi kemampuan keilmuan atau wawasan maupun dari segi kemampuan yang dimiliki, aparat yang mempunyai kreativitas dalam pelaksanaan tugas senantiasa mengacu kepada peraturan perundangundangan yang telah ditetapkan serta memperhatikan ketepatan sasaran dalam pelaksanaan fungsi pelayanan dan menempatkan disiplin serta tanggungjawab sebagai prinsip utama. Untuk itu, apabila aparat yang kurang memiliki sumber dayamanusia, 
aparatyang dimaksud maka kemungkinan hasil yang diperoleh tidak akan maksimal sesuai dengan apa yang diharapkan.

\section{Kesadaran masyarakat}

Salah satu faktor yang turutmem pengaruhi pelaksanaan tugas pelayanan pemerintah di wilayah Kecamatan Samarinda Kota adalah faktor kesadaran masyarakat. Kesadaran masyarakat dimaksudkan ialah kesadaran untuk mempersiapkan segala yang menjadi persyaratan untuk melakukan suatu urusan pelayanan dikantor desa/ kelurahan, relasi antara aparat pemerintah dengan masyarakat memang harus saling mendukung agar dapat mencapai tujuanyang di harapkan,baikitu dari pihak masyarakat maupun dari aparat pemerintah sendiri.

Sesuai pengamatan dilapangan, ada beberapa masyaraka tyang kurang memahami dan menyadari dengan pengurusan yang seharusnya sudah wajib di miliki.oleh nyaitu ,ketika akan melakukan pengurusan seperti KK, KTP, dan AK, keinginan mereka itu segera selesai dengan cepat tetapi merekaka dangm emperhatikan apa yang seharusnya menjadi persyaratan. Dengan keadaan seperti ini, dalam artian kurangnya kesadaran masyarakat bagaimana menciptakan kerjasama antara apatar pemerintah. Sebaliknya, jika mereka benar sadar tanpa harus ada paksaan maka akan menciptakan relasi atau kerjasama yang baik antara pemerintah dengan masyarakat.

\section{Sarana dan prasarana}

Salah satu faktor pendukung ataubisa menjadi penghambat prosedur pelayanan yaitu ketersediaan saranadan prasarana. Dengan adanya sarana pelayanan beraneka ragam jenis dan fungsinya dapat membantu pelayanan pada masyarakat lebih efisien dan efektif. Untuk itu bahwa sarana dan prasarana dapat dikatakan sebagai pendukung disebabkan dapat membantu prsoes pelayanan, begitu pula sebaliknya, jika sarana dan prasarana kurang memadai, maka dapat menghambat prosedur pelayanan. Dari hasil wawancara dengan kepala desa dan kelurahan sarana dan prasarana yang ada dikantor sudah cukup memadai dan sangat menunjang jalannya pelayanan walaupun sarana dan prasarananya masih dikatakan sederhana. 


\section{KESIMPULAN DAN SARAN}

\section{Kesimpulan}

1. Persepsi masyarakat terhadap efektifitas pelayanan public di Kecamatan Samarinda Kota sudah terlaksana dengan baik. Hal ini terbukti dari hasil jawaban para responden berdasarkan hasil penelitian dilihat dari indikator yaitu kesederhaan, kejelasan dan kepastian, keamanan, keterbukaan, ekonomis, keadilan yang merata, dan ketepatan waktu . Dari tujuh indicator tersebut yang menunjukkan hasil responden berada pada kategori sedang. Hal ini berarti bahwa tingkat pelayanannya sudah baik, namun masih perlu ditingkatkan baik dari segi kualitas maupun kuantitasnya.

2. Adapun mengenai faktor-faktor yang mempengaruhi efektifitas pelayanan public di Kecamatan Samarinda Kota berdasarkan hasil penelitian adalah: keadaan sumber daya aparatur, tingkat kesadaran masyarakat dan ketersediaan sarana dan prasarana

\section{A. Saran}

1. Dengan melihat persepsi aparatur pemerintah daerah dalam menjalankan tugas, pokok dan fungsi pelayanan ditinjau dari sikap dan norma-norm, sopan santun dalam pelayanan terhadap masyarakat di kantor desa/kelurahan dan penilaian masyarakat terhadap pelayanan tersebut,diharapkan pemerintah sebagai pelaku utamaatau pengendali jalannyasistem pemerintahan agar bias lebih meningkatkan pelayanan khususnya layanan dibidang administrasi kependudukan dan lebih dekat, selalu memperhatikan kebutuhan masyarakat, memperhatikan segi peningkatan kualitas, kemudahan, ketepatan waktu, ekonomis, serta keamanan dalam memberikan pelayanan.

2. Agar pemerintah lebih memperhatikan,menjaga dan merawat sarana prasarana yang telah ada.

3. Prosedur layanan seyogyanya dilengkapi, sehingga masyarakat dapat lebih memahami dan memperhatikan prosedur dalam memperoleh pelayanan. Jadi pemerintah lebih bekerja keras untuk mensosialisasikan kepada masyarakat akan pentingnya kepemilikan administrasi kependudukan. 


\section{DAFTAR PUSTAKA}

Moenir, H.A.S.2005.Manajemen Pelayanan Umum.Bumi Aksara, Jakarta.

Mitrani, Alain.1995.ManajemenSumber DayaManusia Berdasarkan Kompotensi. Grafiti, Jakarta.

Osborn, David dan Geabler, Ted. 1993. Reinventing Government: How Entrepreneurial Spiritis Transforming the Public Sector. Plume Book, NewYork.

Sampara, Lukman, Sugianto. 2001. Pengembangan Pelaksanaan Pelayanan Prima. LAN RI,Jakarta.

Sampara, Lukman, Sutopo. 2003. Pelayanan Prima.LANRI,Jakarta.

Siagian,P.Sondang.1996.Manajrmen Sumber Daya Manusia. Bumi Aksara, Jakarta.

Sianipar, J.P.1999.Perencanaan Peningkatan Kerja.LAN RI, Jakarta.

Sinambela, Poltak Lijan dkk. 2010. Reformasi Pelayanan Publik. BumiAksara,Jakarta.

Soekanto Soejono. 1995. Penilaian Organisasi Pelayanan Publik. Bumi Aksara, Jakarta.

Syafie,Kencana Inu.2001. Pengantar Ilmu Pemerintahan. Replika Aditama, Bandung.

\section{Literatur Lainnya :}

Keputusan Mendagri No.100/57 Tahun 2002.Diatur lebih lanjut didalam PP No.65 tahun2005 tentang ketentuan standar pelayanan minimal (SPM).

Keputusan Menteri Pendayagunaan Aparatur Negara No.225 tahun 2004 tentang Pedoman Umum Penyusunan Indeks Kepuasan Masyarakat Unit Pelayanan Instansi Pemerintah.

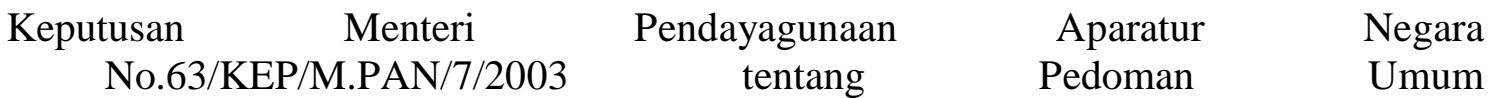
penyelenggaraan Pelayanan Publik.

Undang-UndangNomor 32 tahun 2004 tentang PemerintahanDaerah.

Undang-Undang Nomor 25tahun2004tentangPelayananPublik. 